\title{
EFFECT OF COLD INDUCED PAIN AND MENT AL TASK ON BREATH HOLDING TIME
}

\author{
Kumar $\mathbf{S}^{1}$, Paudel B $\mathbf{H}^{1}$, Dhungel $\mathbf{S}^{1}$, Khadka $\mathbf{R}^{1}$
}

\section{ABSTRACT}

The breath holding time (BHT) is under voluntary control to a considerable extent and is dependent on various factors. Pain interrupts ongoing mental processes and mental task stimulates the respiratory complex as a part of generalised central nervous system arousal. We hypothesised that the concurrent cold-induced pain and mental task may change BHT. In this study BHT with concurrent mental task (MT) or coldinduced pain (CPT) was assessed in healthy individuals $(n=25)$. The objective was to investigate the effect of CPT and MT on BHT. Initially basal BHT was recorded then the BHT was recorded during MT and CPT. The data were analysed by Friedman test. The results showed no significant effect of MT and CPT on BHT. However, BHT showed an increasing trend with CPT and MT. It is concluded that cold pressor pain and mental task do not have vital influence on breath holding time.

Key Words: breath holding time, cold pressor test, pain, mental task.

\section{INTRODUCTION}

Respiration can be voluntarily inhibited for some time but eventually the voluntary control is overridden by involuntary urge to breathe. The point at which breathing can no longer be voluntarily inhibited is called breaking point. If a subject holds his/her breath, he or she can maintain voluntary apnoea for some time before reaching a "breaking point" at which the urgent desire to breathe becomes dominant. During breath holding the alveolar $\mathrm{po}_{2}$ falls and the alveolar $\mathrm{pCo}_{2}$ rises providing obvious reasons for the breaking point. At breaking point, typical figures for alveolar gas

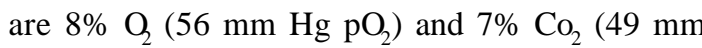
$\mathrm{Hg} \mathrm{pCo}_{2}$ ). The duration of breath holding is limited by several factors including the arterial $\mathrm{pCo}_{2}$ and $\mathrm{pO}_{2}$. However, factors other than chemical are also involved. This is shown by the observation that if, at the breaking point of breath holding, a gas

1. B.P. Koirala Institute of Health Sciences, Dharan, Nepal.

Address for correspondence : Dr. Sanjay Kumar

Assistant professor, Dept. of Physiology

B.P. Koirala Institute of Health Sciences, Dharan, Nepal. 
mixture is inhaled which raises the arterial $\mathrm{pCo}_{2}$ and lowers the $\mathrm{pO}_{2}$, and a further period of breath holding is possible. Breath holding thus depends on the functional status of lungs, development of respiratory muscles, practice, age, sex and psychological factors. Psychological factors play a key role, and subjects can hold their breath longer when they are motivated. ${ }^{1}$ Boiten $^{2}$ reported the effects of emotional behaviour on components of the respiratory cycle. Killian \& Campbell ${ }^{3}$ suggested that required mental concentration stimulated the respiratory complex as part of a generalised central nervous system arousal.

There are lot of studies reporting the effect of task and coping on the respiratory patterns. BHT is a parameter reflecting the functional respiratory status. As stated above, the BHT is not only dependent on chemical factors but various psychological factors have a compounding influence as well. We hypothesised that the concurrent cold induced pain and mental task may change BHT, So, the objectite of the present study was to investigate the effect of cold pressor pain and mental task on breath holding time.

\section{METHODS}

The study was carried out in 25 healthy male volunteers (age $=28 \pm 3.4$ years). The subjects were asked to sit quietly for a few minutes, before the BHT was started. Before recording BHT the subjects were made to understand the procedure. The stethograph was tied around the subjects' chest. The tubing was in partially stretched position. The stethograph was connected to the volume transducer. The observer used a stopwatch to record the time for each observation. For stethographic records Student Physiograph (Inco, Ambala, India) with strain gage coupler (S01) and volume transducer (Vt. 1620, T-303) were used. Initially few control respiratory excursions were recorded.
The subjects were asked to pinch their nostrils with the thumb and forefinger, and hold breath after a maximal deep inspiration. Baseline breath holding time was recorded by a stopwatch as well as on chart paper run on Physiograph. After normalising the respiratory excursions the subjects were asked to repeat the procedure dipping their non-dominant hand up to the first proximal wrist crease in icecold $\left(5^{\circ} \mathrm{C}\right)$ water. ${ }^{4,5}$ They were asked to take out hand when the pain became intolerable but keep holding the breath. The pain index was recorded using visual analogue scale (VAS) after cold pressor test. The subjects were asked to grade their pain intensity on a 0-10 horizontal scale ${ }^{6}$ with the two extreme endpoints labelled as 'no pain' and 'worst pain ever'. They had to place a mark on the $10-\mathrm{cm}$ line at a point, which corresponds to the level of pain intensity. The distance in centimetres from the lower end of the VAS to the subject's mark was used as a numerical index of the pain severity.

After the respiratory movements were normalised the subjects did mental performance task ${ }^{7}$ during breath holding. Mental performance task was to subtract sevens from 100 (i.e. 100, 93, 86, 79...). Different time intervals of BHT were calculated measuring the duration from chart paper as well as reading from stopwatch (Table I).

\section{RESULTS}

The mean age of the subjects was $28 \pm 3.4$ years. The data were tested for their frequency distribution. Then the baseline BHT, BHT+MT and $\mathrm{BHT}+\mathrm{CPT}$ were compared with each other using non-parametric Friedman repeated measures (Table I). Tukey's multiple comparisons were done (Basal*MT*CPT) in all the three sets of data (BHT, DF and BHT-DF) and at $\mathrm{p}<0.05$ significance level the ranks of any two sets were not significantly different. 


\section{Table I}

Effect of cold-induced pain and mental task on breath holding time and its components

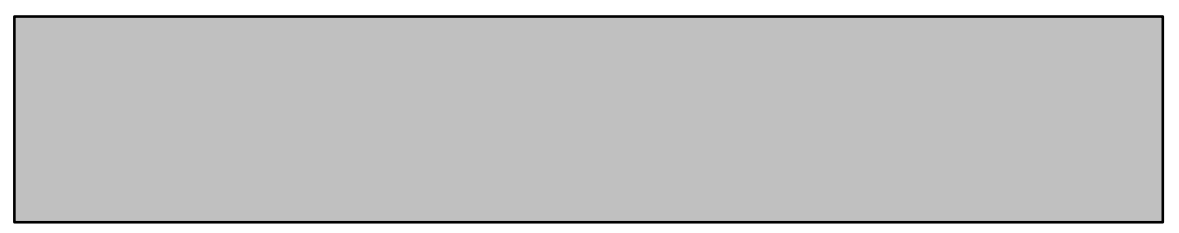

All the intervals are in seconds and presented as mean $\pm S D$. CPT: cold pressor test; $\chi^{2}$ : chi-square; BHT: breath holding time; DF: duration from beginning of breath holding to the onset of diaphragmatic flutter; BHT - DF: BHT minus DF.

\section{DISCUSSION}

The present study was aimed at investigating the effect of mental task and cold-induced pain on breath holding time. Breathing is under voluntary control within limits. ${ }^{8}$ Holding the breath voluntarily opposes ventilatory drive suggesting two opposing factors operating during the process i.e. the ventilatory drive and the voluntary inhibition of ventilation. Psychological factors like motivation can increase BHT. ${ }^{1}$ The parts of the brain such as limbic system and hypothalamus can affect pattern of breathing e.g. in affective states such as rage and fear. Cold-induced acute pain is known to increase various cardio-respiratory parameters e.g. rate and tidal volume indicating its stimulatory effect on ventilation. ${ }^{9}$ Breath holding attacks occur in infants and young children and are generally precipitated by emotional distress, such as fright, frustration, pain or anxiety. It is known that pain demands attention and interrupts ongoing mental processes. This often serves an adaptive purpose as pain functions to alarm against harm by taking priority over other competing demands upon attention. A number of studies have reported the detrimental effect of chronic pain upon concentration, attention focus, learning and memory. ${ }^{10,11,12}$ In contrary to previous reports of interaction between pain and respiratory function, the results of present study showed no significant effect of cold-induced pain on BHT. It can be argued that the pain stimulus was inadequate. But the coldinduced (water temperature $=5.35 \pm 0,38^{\circ} \mathrm{C}$ ) pain intensity (VAS $=7.8 \pm 1$ ) was sufficient enough to have its significant physiological effects. Absence of differences between BHT and BHT+CPT in the present study could be because of lack of strong physiological interaction between pain and breathholding mechanisms. This promoted us to speculate that both of these mechanisms may have parallel processing with minimal interaction.

Killian \& Campbell ${ }^{2}$ suggested that required mental concentration stimulated the respiratory complex as part of a generalised central nervous system arousal. Mental task being a sufficiently strong stimulus for generalised arousal it had no significant effect on BHT in the present study. The data indicated only some trend towards increment of the BHT with mental task and cold-induced pain.

Similarly both the interventions were also not different significantly from each other. It shows that both the interventions had identical physiological effects. Thus, our a priori hypothesis was rejected. Psychological factors (cold-induced pain and mental task) used in the present study had no effect on breath holding time. The likely mechanism is that breath-holding mechanism visa-vis pain and mental task may have parallel processing without vital interaction among them. However, there was a trend showing an increase 
in BHT after MT or CPT. This could be simply because of effect of training or change in motivation level after baseline breath holding manoeuvre. All the records showed diaphragmatic flutter. There was no statistically significant difference between the 'times of onset of diaphragmatic flutter' with pain and mental task (Table 1). It can be concluded that the concurrent pain and mental task have no substantial effect on the breath holding time. Further studies are required to explore the degree of interaction among these mechanisms.

\section{REFERENCES}

1. Ganong WF. Review of Medical Physiology, 19th ed., Appleton \& Lange, USA, 1999; 647.

2. Boiten FA. The effects of emotional behaviour on components of the respiratory cycle. BiolPsychol 1998; 49(1-2): 29-51.

3. Killian KJ \& Campbell EJ M, Dyspnea. In: The Lung. RG Crystal, JB West, ER Weibel and PJ Bames (Eds. ), 2nd Ed., Vol 2, Lippincott - Raven, 1997; 1868-1869.

4. Hines EAJ r., Brown GE. The cold pressor test for measuring the reactivity of the blood pressure. Data concerning 571 normal and hypertensive subjects. Am HJ 1936; 11:1-9.
5. Wolf S, hardy JD. Studies on pain: Observations on pain due to local cooling and on factors involved in the cold pressor effect. J Clin Invest 1994; 20: 521-533.

6. Huskisson EC. Visual analogue scales. In: Melzack $\mathrm{R}$ (ed.,) Pain measurement and assessment. Raven Press, New York, 1993; 33-37.

7. Swash M. Hutchison's clinical methods, 20th ed., ELBS \& Saunder's Company Ltd, London, 1997; 281.

8. West John b. Best and Taylor's physiological basis of medical practice, 12th ed., Williams and Wilkins, Baltimore, 1990; 580,

9. Tandon OP, Ffimani A \& Singh S. Pulmonary responses during cold induced acute pain. Indian J Physiol Pharamacol 1997; 41(1): 16-22.

10. Jamison RN, Sbrocco T\& Parris WC. The influence of problems with concentration and memory on emotional distress and daily activities in chronic pain patents. IntJ Psychiatry Med 1988; 18: 183-191.

11. Dufton B. Cognitive failure in chronic pain. Int J Psychiatry Med 1989; 19: 291-297.

12. Kewman DG, Vaishampayan N, Zaid D \& Han B. Cognitive impairment in musculoskeletal pain patients. Int J Psychiatry Med 1991; 21: 253-262. 